\title{
CONTRIBUCIÓN DEL SISTEMA DE PENSIONES PRIVADO DE CAPITALIZACIÓN INDIVIDUAL AL DESARROLLO DEL MERCADO DE CAPITALES EN BOLIVIA 1997- 2009
}

\section{Pamela Córdova Olivera}

\section{RESUMEN}

El establecimiento del Sistema de Pensiones de Capitalización Individual en Bolivia aprobado en el año 1996, constituye el reemplazo de un sistema tradicional de reparto colectivo, de contribuciones comunes y administradas por el Estado, por un sistema de capitalización individual, de contribuciones definidas y administradas por el sector privado. A más de una década de su establecimiento, es posible realizar una estimación más completa y precisa de sus resultados e impactos. Este estudio presenta una evaluación cualitativa y cuantitativa del impacto de los Fondos de Pensiones de Capitalización Individual sobre el desarrollo del Mercado de Capitales en Bolivia en lo que respecta a su regulación, composición, tamaño y profundidad financiera considerando alternativamente la participación del sector privado y público. Como base de demostración empírica, se plantea un modelo econométrico basado en el análisis de series de tiempo cointegradas que hacen hincapié en los factores financieros concentrados en una variable de profundidad financiera, cuyo resultado confirma el importante aporte del Sistema de Pensiones Privado a la mejora en la calidad de regulación, tamaño, trasparencia y crecimiento del mercado financiero en Bolivia.

Palabras Clave: Sistema de Pensiones, Fondo de Capitalización Individual, Mercado de Capitales, Profundidad Financiera, Series de Tiempo Cointegradas. 